commercial and social sciences library, technical library, science library, technical documents unit, patents library and microfilm unit. In the arts the library includes a Commonwealth library, an American library, international library, biography library, reference issue foyer, and a record office and local history library. The booklet displays well the regional character of the libraries and their services, and it should be noted that they are depository libraries for the publications of the American, British and European Atomic Energy Commissions, and for the publications of the United Nations Organization and the United Nations Educational, Scientific and Cultural Organization.

\section{Library of the U.S. Naval Observatory}

AN article by Marjorie S. Clopine, librarian of the United States Naval Observatory, reprinted from Special Libraries (52, No. 2, February 1961) and issued by the Observatory as Reprint No. 19, describes the resources and treasures of the Library, which are of particular interest for astronomers. By 1960 the Library contained more than 55,000 catalogued volumes and also many sets of periodicals, the mathematics collection being especially strong in analysis and noted for its value in reference work. There is a collection of 500 rare books printed before 1800 . Besides long sets of nautical almanacs, the Library has a valuable collection of star catalogues and charts, observatory publications, bibliographical reference works in astronomy, the complete works of many astronomers and mathematicians, and mathematical tables.

\section{Chemical and Allied Industries at the Science Museum Library}

UNDER the title Books on the Chemical and Allied Industries the Science Museum Library has issued, for the Ministry of Education, a short-title list of books published in 1930 and onwards on the chemical industry, with books on mining and metallurgy, and the paper, leather and textile industries and received in the Science Library up to the end of 1959 (Pp. ix + 118. London: H.M.S.O., 1961. 12s. 6d. net). The list has been compiled by L. R. Day from the subject catalogue in the Library and is the second in a series of catalogues, each carrying a large division of the Science Library's collection. Entries are arranged in broad subject groups selected from the Universal Decimal Classification, and both an author index and a subject index are included. While intended primarily to enable users to take advantage of books available in the Library it is hoped that the list will assist other libraries in both the selection and classification of works in these fields. A Supplement, issued as Science Library Bibliographical Series No. 781, includes books received in the Science Library in 1960 (Pp. 10. London: Science Museum, 1961).

\section{New American Electricity Plant}

THE largest power plant in the western hemisphere has recently begun to operate on the United StatesCanadian border. It harnesses the power of the River Niagara, which drops $325 \mathrm{ft}$. over eataracts and falls in its 34-mile course between Lake Erie and Lake Ontario. The new hydro-electric development, one of the world's largest, is the Robert Moses Niagara Power Project. The power output of its two generating plants is $2,190,000$ kilowatts, exceeding the giant United States' Grand Coulee Dam. The new Niagara River project began power production three years to a day after contracts for its construction were signed. Construction has been rushed and limited operation started because of a power shortage that has existed since 1956, when a power plant was destroyed by a rock-slide at Niagara Falls. Only two of the plant's 13 generators are now operating, but the remaining 11 will be completed and placed in use at the rate of one each five months. The Robert Moses Niagara Power Project, built by the New York State Power Authority and named after its first chairman, is a 720,000,000-dollar nonprofit undertaking, financed through the sale of bonds to private investors. Cost of the plant and interest to investors will be paid through the sale of electricity. Several utility companies have contracted to buy the plant's electrical output. Because of limitations of water-diversion, the United States' share of river-flow during daylight in summer is not sufficient for continuous operation of the new plant. To ensure a constant water supply, the Robert Moses project includes a 1,880-acre storage reservoir which will be filled through diversion of Niagara River water during the winter. The reservoir, however, is more than an alternative source of water for operation of the power plant. It has been equipped with a reversible pump-generating system, and is used for production of 240,000 kilowatts of electricity.

\section{Coal Tar Technology}

Review of Coal Tar Technology, for the first half of 1960 , presents the customary authoritative survey of international research, development, production, purification and patents relative to coal tar and its products covering that period. (January-June, 1960, 12, Part 1. Pp. ii +63 . Gomersea, Leeds: Coal Tar Research Association, 1960. 20s. per volume.) Section 1 reviews the then current work on coal tar itself, the primary fractions light oils, benzole, pitch and bitumen; tar acids; tar bases; monocyclic and polycyclic aromatic hydrocarbons; also utilization, which ranges from road tar, paints, pipecoatings, solid and liquid fuels, lubricants, plastics and resins, to wood preservatives and pesticides. Section 2 is devoted to general chemistry and chemical technique of coal tar and products; space is taken up chiefly with catalytic processes, for example, alkylation, isomerization, hydrogenation, oxidation, desulphurization, cracking. Physical chemistry of these substances concerns mainly rheology, vapour pressure and thermal properties. The paragraphs on analytical work include spectroscopic and chromatographic applications to coal tar and products, while a concluding category of chemical techniques describes recent work in connexion with distillation and crystallization problems.

\section{Glossary of Petroleum Terms}

THE Glossary of Petroleum Terms, first published in 1951, with a second edition in 1955 , has now been revised and enlarged, bringing it up to date. (Third edition, revised and enlarged. Edited by George Sell. Pp. vii + 39. London: Institute of Petroleum, 1961. 5s.) The petroleum industry is no exception to the trend of many others in developing over the years of its evolution a colloquial vocabulary understood only by those engaged in its day-to-day pursuits. In fact, especially in English-speaking international environments, the particular 'jargon' involved is, to the layman, probably more incomprehensible than in the case of many other modern, comparable commercial undertakings. Such words 